\title{
Predictive Impact of Resilience on Depressive Symptoms in Adolescents with High Functioning Autism Spectrum Disorders
}

\author{
Charity N. Onyishi ${ }^{1,2} \&$ Maximus M. Sefotho ${ }^{1}$ \\ ${ }^{1}$ Department of Educational Psychology, University of Johannesburg, South Africa \\ ${ }^{2}$ University of Nigeria, Nsukka, Nigeria \\ Correspondence: Charity N Onyishi, Department of Educational Psychology, University of Johannesburg, \\ South-Africa. ORCID: 0000-0003-4047-7850. Tel: 27-63-114-8113. E-mail: cnonyishi@uj.ac.za
}

Received: August 18, 2019 Accepted: November 8, 2019 Online Published: December 12, 2019

doi:10.5539/gjhs.v11n14p73 URL: https://doi.org/10.5539/gjhs.v11n14p73

\begin{abstract}
Adolescents with high functioning Autism Spectrum Disorders (ASDs) are highly vulnerable to depressive symptoms (DS) and a range of mental health problems compared to their typically developing peers. It is not known whether resilience can influence DS in adolescents with high functioning ASD. This study sought to find out the link between resilience and DS in a sample of adolescents with high functioning ASD in Nigeria. The study is a quantitative correlation study of in-school adolescents with high functioning ASD. 68 adolescents with high functioning ASD from 20 inclusive education schools participated in the study. Data were collected using self report versions of Child and Youth resilience Measure (CYRM-SR) and Children's Depression Inventory second edition (CDI-2: SR). Findings showed that total resilience score is a strong negative predictor of DS in adolescents with high functioning ASD $(\mathrm{B}=-.93 ; \beta=-.77 ; \mathrm{t}=-4.20 ; \mathrm{p}=.000)$. Specifically, individual capacities subscale $(B=-2.20 ; \beta=-.77 ; t=-8.39 ; p=.000)$, Primary caregivers resources subscale $(B=-1.98 ; \beta=-.69 ; t=-7.49 ; p=.000)$; and Contextual factors subscale $(\mathrm{B}=-2.02 ; \beta=-.62 ; \mathrm{t}=-8.38 ; \mathrm{p}=.000)$ predicted overall depressive symptoms (Total DS score) negatively and significantly. It was concluded that DS among adolescents with high functioning ASD can be reduced through developing resilience skills among them. Parents, special Educators and all stakeholders should intensify efforts in building resilience in adolescents with high functioning ASD.
\end{abstract}

Keywords: autism spectrum disorders, depression, resilience, adolescence

\section{Introduction}

Autism Spectrum Disorders (ASDs) are increasing in prevalence and affect the greatest number of children and adolescents with Neuro-developmental disorders worldwide (Chinawa, Manyike, Aniwada, Chinawa, Obu, Odetunde, Nwokocha, \& Ibekwe, 2016). ASDs are characterized by poor social interaction and communication, as well as restricted, repetitive, and stereotyped patterns of behaviour (American Psychiatric Association, 2013). Biological factors including atypical heart rates, neural reactivity and sensory processing problems tend to make individuals with autism vulnerable to depressive symptoms (Case-Smith, Weaver \& Fristad, 2015; Pitskel, Bolling, Kaiser, Pelphrey \& Crowley, 2014; Mazefsky, 2015; Vazquez, Blood, Wu, Chaplin, Hommer, Rutherford, \& Crowley, 2016). Thus depression is one of the highest co morbid disorders of autism (Matson \& Williams, 2013; Mazzone, Ruta, \& Reale, 2012).

Additionally, environmental threats, such as bullying (Cappadocia, Weiss, \& Pepler, 2012), challenging academic experiences (Ashburner, Ziviani, \& Rodger, 2010), poor social relationships (Calder, Hill, \& Pellicano, 2013), transition through developmental stages and stigma (Anderson, Sosnowy, Kuo, \& Shattuck, 2018; Brede, Remington, Kenny, Warren, \& Pellicano, 2017), tend to aggravate depressive conditions among ASD population. Furthermore, poor social skills in AWASD results in reduced number of friendships, which are linked with the manifestation of depressive symptoms among adolescents with ASD (Schiltz et al., 2018). Poor cognitive abilities associated with lack of, or poor theory of mind (Bauminger, Solomon, \& Rogers, 2010) and low verbal abilities tend to decrease peer relatedness, increase loneness and feeling of rejection, which collectively threaten their self-esteem (Schiltz et al., 2018).

Hence, depressive symptoms are more frequently pragmatic in people with ASD, compared to their typically developing peers (Bitsika \& Sharpley, 2015). There is about 70\% prevalence of depressive symptoms among 
individuals with ASD (Center on Secondary Education for Students with ASD (CSESA) 2014; Matson et al., 2007; Mayes, Calhoun, Murray, \& Zahid, 2011; Salazar et al., 2015), with about 20\% developing clinically significant depressive disorders (Matheis \&Turygin, 2016). Research shows a higher rate of suicide among individuals with ASD compared to their typically developing peers (Kirby, Bakian, Yue, Bilder, \& Keeshin, 2019), with 10\% - 72\% of the incidences linked to depression (Matheis \& Turygin, 2016; Salazar, Baird, Chandler, Tseng, O'sullivan, Howlin, Pickles, \& Simonoff, 2015).

In adolescents with ASD, depression is symptomatized in emotional dysfunctioning such as increased moodiness, irritability, sadness, fearfulness; loss of appetite and sleep (Gotham, Unruh, \& Lord, 2015). Behavioral symptoms may include: aggression, decrease in self-care; losing of previously learned skill; increased autistic symptoms and or expressions of suicide or self-destructive behaviors (DeFilippis, 2018; Gotham et al., 2015). Empirical studies show that age and IQ (DeFilippis, 2018; Mayes, Calhoun, Murray, \& Zahid, 2011) are more associated with depressive symptoms in ASD than gender, or socio-economic and familial factors (Mayes, Calhoun, Murray, \& Zahid, 2011).

Hence, there could be increased tendency of depressive symptoms in adolescents with autism (De-la-Iglesia \& Olivar, 2015). On the other hand, the upheavals associated with developmental stage of adolescence tend to bring in a measure of mood fluctuation even in typically developing adolescents (Casey et al., 2010). In the case of adolescents with high functioning autism, their plight is aggravated by their social awareness, compared to those with in the low functioning spectrum. This is because; this group is characterized by normal verbal and mental abilities and the presence of slightly abnormal development in the areas of social interaction and communication, as well as by the presence of restricted, repetitive behavior (Schiltz et al., 2018).

Consequently, adolescents with high functioning ASD are at increased risk of depression due to their self and social awareness of deficit and greater expectations placed on them (DeFilippis, 2018). Further, they are under-served and misunderstood by the society as possessing "almost normal language ability and intelligence" (Feather, 2015). However, because they experience social difficulties, and sensory and motor issues, most adolescents succumb to depression (Huang \& Wheeler, 2015). Depression in adolescents with high functioning autism can manifest as emotional dysfunctioning (Gotham, Unruh, \& Lord, 2015) and behavioral symptoms including but not limited to moodiness, aggression, decrease in self-care; losing of previously learned skill; increased autistic symptoms and or expressions of suicide or self-destructive behaviors (DeFilippis, 2018). For the purpose of the present study, depressive symptoms were measured in five dimensions, including negative mood, ineffectiveness, Anhedonia, negative self-esteem and interpersonal problems (Logan et al., 2013), especially when the adolescents lack resilience skills necessary for dealing with daily challenges.

Resilience is a dynamic process that enables an individual to adapt functionally and/or withstand significant risks and threatening circumstances without showing psychological or physical symptoms (Lai \& Szatmari, 2019; Masten \& Tellegen, 2012; Ungar \& Liebenberg, 2011; Bitsika \& Sharpley, 2013). More recently, resilience has been described as qualities of both the individual and the environment that potentiate affirmative growth(Lai, et al., 2019; Masten et al., 2012; Ungar et al., 2011; Bitsika \& Sharpley, 2013) in culturally pertinent ways. Resilience in adolescents with high functioning ASD may reduce negative physical and psychological reactions and help them navigate threats and demonstrate positive outcomes (Masten \& Tellegen, 2012; Ungar \& Liebenberg, 2011; Bitsika \& Sharpley, 2013). Evidences show that resilience could buffer against depression in parents with children with ASD, and in typically developing adolescents (Bitsika \& Sharpley, 2013; Anyan \& Hjemdal, 2016). It is not known whether resilience would predict DS in adolescents with high functioning ASD. We sought to investigate the predictive impact of resilience on depressive symptoms among in-school adolescents with high functioning autism in Nigeria. This can provide the knowledge base for development of interventions, prevention and reduction of depressive symptoms among autistic population.

\section{Method}

\subsection{Study Design and Participants}

This was a quantitative descriptive study carried out in inclusive-based middle and upper basic education schools in the 5 states (Abia, Anambra, Ebony, Enugu, and Imo States) of South-East Nigeria. The first author and two research assistants visited 4 inclusive schools ( 2 primary and 2 secondary schools) in each state giving a total of 20 inclusive (10 primary and 10 secondary) schools. A total of 68 adolescents with high functioning ASD (46 males and 12 females) who met the inclusion criteria for the study participated in the study. Inclusion criteria included that i) the adolescent must have been formally diagnosed with ASD; ii) is in inclusive secondary school; iii) is with high functioning autism (ie, individual is in the group of low support need); iv) the individual is within the ages of 12 to 23 years. 


\subsection{Measures and Data Collection}

Measures of Depressive symptoms: Self-report version of the Children's Depression Inventory second edition (CDI-2: SR) (Kovacs, 2014) was used to assess depressive symptoms in the participants. The (CDI- 2:SR) consists of 28 items in a 3-point scale ranging from $0-2$, which provides a total score (T-score $=0-56$ ), as well as 5 subscale scores indicating negative mood/physical symptoms, negative self-esteem, interpersonal problems, anhedonia and ineffectiveness. The CDI-2: SR has been found to have high psychometric properties in other countries (De-la-Iglesia \& Olivar, 2015: Logan et al., 2013). A Crombach Alpha $\alpha=.77$ was found in Nigerian the context.

Measures of Resilience in Adolescents with ASD: We used Child and Youths' Resilience measure (CYRM), self-report (CYRM-SR-26) version (Ungar, \& Liebenberg) to measure resilience in adolescents with high functioning ASD. The CYRM-SR-26 is rated in 3-point scale of No (0.00), Sometimes (1.00), Yes (2.00), with three Resilience Monkeys showing the three dispositions. The instrument was so interesting using it among adolescents with high functioning ASD due to their craving for visual materials. The instrument has three major subscales measuring three resilience factors (individual capacities/resources, relationships with primary caregivers and contextual factors). The total resilience (T-R) score is a summation of the scores from items 1 to 26 (T-R=52); individual capacities subscale measures personal skills Peer support; and social skill. Primary caregiver's resources subscale measures physical care giving and caregivers' psychological supports. Contextual factors subscale measures spiritual, education and cultural dimensions. The reliability index of the instrument was .83 in Nigeria youths with ASD.

The CDI-2: SR and CYRM-SR-26 were administered to the participants in their school halls during break period. Data collection lasted for 10weeks as the researcher and the research assistants visited two schools in a week for collection of data. All the questionnaires administered were retrieved on-the spot.

\subsection{Ethical Considerations}

Ethical approval was obtained from the Faculty of Education Research Ethics Committee of University of Nigeria, Nsukka. Informed consent was obtained from all participants and their parent/caregivers before engaging them in the research. Also, participating in the research was voluntary for all the participants.

\section{Data Analysis and Results}

Data were analyzed using mean, standard deviations, Pearson product-moment correlation and linear regression analysis (p-values set at 0.05; Confidence Intervals (CIs) at 95\% level).

Table 1. Pearson correlation coefficients among Resilience subscales and depressive symptoms in Adolescents with ASD

\begin{tabular}{|c|c|c|c|c|c|c|c|c|c|c|c|c|}
\hline Mode & Variable & $\mathrm{M} \pm \mathrm{SD}(\mathrm{N}=68)$ & 1 & 2 & 3 & 4 & 5 & 6 & 7 & 8 & 9 & 10 \\
\hline 1 & Resilience Total score & $19.39 \pm 8.45$ & 1 & $.90 * * *$ & $.93 * * *$ & $.83 * * *$ & $-.59 * * *$ & $-.79 * * *$ & $*-.76 * * *$ & $*-.55 * * *$ & $-.75 * * *$ & $-.62 * * *$ \\
\hline 2 & IndRscore & $8.09 \pm 3.39$ & & & $.76 * * *$ & $.62 * * *$ & $-.77 * * *$ & $-.71 * * *$ & $*-.69 * * *$ & $*-.72 * * *$ & $-.69 * * *$ & $-.68 * * *$ \\
\hline 3 & PrimaryCareGiver & $5.39 \pm 3.57$ & & & & $.67 * * *$ & $-.68 * * *$ & $-.71 * * *$ & $*-.66 * * *$ & $*-.63 * * *$ & $-.63 * * *$ & $-.66 * * *$ \\
\hline 4 & ContexualResilience & $5.91 \pm 2.48$ & & & & & $-.52 * * *$ & $-.63 * * *$ & $*-.69 * * *$ & $*-.67 * * *$ & $-.69 * * *$ & $-.72 * * *$ \\
\hline 5 & Depression Total & $40.32 \pm 10.26$ & & & & & & $.72 * * *$ & $.98 * * *$ & $* .97 * * *$ & $.96 * * *$ & $.94 * * *$ \\
\hline 6 & NegativeMood & $8.93 \pm 2.24$ & & & & & & & $.90 * * *$ & * $.87 * * *$ & $.832 * * *$ & $.82 * * *$ \\
\hline 7 & Ineffectiveness & $8.87 \pm 2.36$ & & & & & & & & $.96 * * *$ & $.93 * * *$ & $.91 * * *$ \\
\hline 8 & Anhedonia & $7.46 \pm 2.09$ & & & & & & & & & $.94 * * *$ & $.91 * * *$ \\
\hline 9 & NESelfEsteem & $7.42 \pm 1.96$ & & & & & & & & & & $.92 * * *$ \\
\hline 10 & IntPersonalProblems & $7.57 \pm 2.03$ & & & & & & & & & & \\
\hline
\end{tabular}

Correlation coefficients were transformed using Fisher r-to-z transformation. $* * *=\mathrm{p}<0.001$.

Data in Table 1 show the mean, standard deviation as well as the correlation coefficients of resilience and depressive symptoms in the participants. Considering the mean and standard deviation, the participants generally had low mean scores in all the dimensions of resilience. A low total resilience score was recorded (19.39 \pm 8.45$)$ which is a total of individual mean scores of each dimension of resilience. Specifically the participants' mean 
scores were low in the individual resilience (8.09 \pm 3.39$)$, primary caregiver relationship $(5.39 \pm 3.57)$ and contextual resilience (5.91 \pm 2.48$)$. On the other hand, their total depression score was high $(40.32 \pm 10.26)$ based on the cut of score. The specific depressive symptoms scores were also high, including negative mood (8.93 \pm 2.24$)$, ineffectiveness (8.87 \pm 2.36$)$, anhedonia (7.46 \pm 2.09$)$, negative self-esteem (7.42 \pm 1.96 ) and interpersonal problems (7.57 \pm 2.03 ). These results indicate that adolescents with high functioning autism have high level of depressive symtoms and low resilience factors.

To find out the extent to which resilience factors could account depressive symptom, we sought to find out the relationship between the dependent variables (depressive symptoms) and independent variables (resilience dimensions).Table 1 further shows that the total resilience score as well as all the dimensions of resilience had statistically significant negative correlation ( $\mathrm{p}$-value $=.000)$ with depressive symptoms (DS). Specifically, total resilience score (T-R) correlated significantly with interpersonal problem (IPP) $\left(r^{2}=-.62\right)$, negative self-esteem (NSE) $\left(r^{2}=-.75\right)$, Anhedonia $\left(r^{2}=-.55\right)$, ineffectiveness $\left(r^{2}=-.76\right)$, Negative mood $(\mathrm{NM})\left(\mathrm{r}^{2}=-.79\right)$ and the total depression score (T-DS) $\left(\mathrm{r}^{2}=-.59\right)$. The individual resilience factor score $(\mathrm{I}-\mathrm{R})$ similarly had high correlation with each of the DS: IPP $\left(r^{2}=-.68\right)$, NSE $\left(r^{2}=-.69\right)$, Anhedonia $\left(r^{2}=-.72\right)$, ineffectiveness $\left(r^{2}=-.69\right), N M\left(r^{2}=-.71\right)$ and the T-DS $\left(r^{2}=-.77\right)$. Primary caregiver resources (PC-R) also correlated with all the DS: IPP $\left(r^{2}=-.66\right)$, NSE $\left(r^{2}=-.63\right)$, Anhedonia $\left(r^{2}=-.63\right)$, ineffectiveness $\left(r^{2}=-.66\right), \mathrm{NM}\left(\mathrm{r}^{2}=-.71\right)$ and the T-DS $\left(\mathrm{r}^{2}=-.68\right)$. Contextual resources $(\mathrm{CR})$ dimension correlated significantly with IPP $\left(r^{2}=-.72\right)$, NSE $\left(r^{2}=-.69\right)$, Anhedonia $\left(r^{2}=-.67\right)$, ineffectiveness $\left(r^{2}=-.69\right), \mathrm{NM}\left(\mathrm{r}^{2}=-.63\right)$ and the T-DS $\left(\mathrm{r}^{2}=-.52\right)$.

Table 2. Regression Analysis for the predictive validity of Resilience dimensions on Depressive symptoms

\begin{tabular}{|c|c|c|c|c|c|c|c|c|c|c|c|c|c|c|c|c|c|c|c|c|c|c|c|c|}
\hline \multirow{2}{*}{$\begin{array}{l}\text { Indepent } \\
\text { Variable }\end{array}$} & \multicolumn{4}{|c|}{ T-Depression } & \multicolumn{4}{|c|}{ Negative Mood } & \multicolumn{4}{|c|}{ Ineffectiveness } & \multicolumn{4}{|c|}{ InterPersProblems } & \multicolumn{3}{|c|}{ Anhedonia } & \multicolumn{5}{|c|}{ Negative self-esteem } \\
\hline & B & $\beta$ & $\mathrm{t}$ & $\mathrm{p}$ & B & $\beta$ & $\mathrm{t}$ & $\mathrm{P}$ & B & B & $\mathrm{t}$ & $\mathrm{p}$ & $\mathrm{B}$ & $\beta$ & $\mathrm{t}$ & $\mathrm{p}$ & B & B & $\mathrm{T}$ & $\mathrm{p}$ & B & $\beta$ & $\mathrm{t}$ & $\mathrm{p}$ \\
\hline 1 Tota & is & $\stackrel{\prime}{\square}$ & i̊ & $\dot{8}$ & i் & : تُ & $\stackrel{\vec{\omega}}{\sigma}$ & ஜ & $\stackrel{i}{\text { in }}$ & $\dot{\ddot{\alpha}}$ & $\frac{\dot{b}}{\dot{N}}$ & $\dot{8}$ & $\dot{H}_{0}^{\prime}$ & $\stackrel{\dot{y}}{y}$ & 岂 & $\dot{8}$ & $\stackrel{1}{\sigma}^{\prime}$ & $\stackrel{\dot{u}}{u}$ & $\begin{array}{l}\dot{\phi} \\
\dot{\omega}\end{array}$ & $\dot{8}$ & $\therefore$ & $\stackrel{1}{u}$ & $\begin{array}{l}\dot{\infty} \\
\dot{\infty}\end{array}$ & $\dot{8}$ \\
\hline $2 \begin{array}{l}\text { Individual-R } \\
\text { score }\end{array}$ & ì & $\stackrel{\dot{y}}{\mathrm{y}}$ & dُ & $\dot{8}$ & $\stackrel{1}{ \pm}$ & $\stackrel{\dot{y}}{\prime}$ & $\stackrel{\dot{1}}{\infty}$ & 8 & $\stackrel{1}{+}$ & ¿̇ & $\dot{\dot{a}}$ & ஜ் & 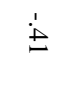 & $\dot{\infty}$ & $\stackrel{\dot{\omega}}{\dot{\omega}}$ & ஜ & $\dot{\dot{f}}$ & $\stackrel{1}{N}$ & $\stackrel{\dot{\infty}}{\dot{\omega}}$ & $\dot{8}$ & $\stackrel{1}{\Delta}$ & g் & $\stackrel{\dot{y}}{\dot{y}}$ & \& \\
\hline 3 Care-Rscore & $\frac{1}{\infty}$ & 'ृ் &  & $\dot{8}$ & 离 & $\stackrel{\dot{y}}{\prime}$ & $\stackrel{\dot{\omega}}{\stackrel{\omega}{\omega}}$ & छ & $\dot{1}$ & $\dot{\alpha}$ & ف̊̀ & छे & $\dot{\omega}_{\infty}^{i}$ & à & $\dot{d}$ & \& & نِ & '. & فं & \&े & ني & $\dot{\not}$ & do & $\dot{8}$ \\
\hline $4 \begin{array}{l}\text { Contexual-R } \\
\text { score }\end{array}$ & $\begin{array}{l}1 \\
\text { in } \\
\text { N }\end{array}$ & & $\sigma$ & 8 & $\dot{\alpha}$ & : & $\dot{\infty}_{\omega}^{\infty}$ & $\dot{8}$ & ă & فे & $\stackrel{\dot{y}}{\dot{u}}$ & ¿े & ing & $\dot{N}_{N}^{\prime}$ & $\stackrel{\infty}{=}$ & ¿े & ¿ू' & $\dot{3}$ & $\dot{\dot{\omega}}$ & $\dot{8}$ & ü & ชิ & $\dot{\vec{a}}$ & $\dot{8}$ \\
\hline
\end{tabular}

Considering the $\mathrm{B}$ and $\beta$ weights in regression analysis (Table 2), the T-R was a strong negative predictor of the total $\mathrm{DS}$ score $(\mathrm{B}=-.93 ; \beta=-.77 ; \mathrm{t}=-4.20 ; \mathrm{p}=.000), \mathrm{NM}(\mathrm{B}=-.40 ; \beta=-.79 ; \mathrm{t}=-10.39 ; \mathrm{p}=.000)$, ineffectiveness $(\mathrm{B}=-.21$; $\beta=-.76 ; t=10.39 ; p=.000), \operatorname{IPP}(B=-.49 ; \beta=-.77 ; t=-9.37 ; p=.000)$, anhedonia $(B=-.39 ; \beta=-.75 ; t=-8.93 ; p=.000)$, and NSE $(B=-.57 ; \beta=-.75 ; t=-8.98 ; p=.000)$. These indicate that at every unit increase in the TR score, total DS decreases by .93; NM decreases by .40; IEF decreases .21; IPP decreases by .79; AN decreases by .49 and NSE decreases by .57. More specifically, IR score was the highest predictor of DS $(B=-2.20 ; \beta=-.77 ; t=-8.39 ; p=.000)$, $\mathrm{NM}(\mathrm{B}=-.47 ; \beta=-.71 ; \mathrm{t}=-7.87 ; \mathrm{p}=.000)$, ineffectiveness $(\mathrm{B}=-.48 ; \beta=-.70 ; \mathrm{t}=-7.64 ; \mathrm{p}=.000), \operatorname{IPP}(\mathrm{B}=-.41 ; \beta=-.68$; $\mathrm{t}=-7.37 ; \mathrm{p}=.000)$, anhedonia $(\mathrm{B}=-.44 ; \beta=-.72 ; \mathrm{t}=-8.13 ; \mathrm{p}=.000)$, and NSE $(\mathrm{B}=-.40 ; \beta=-.69 ; \mathrm{t}=-7.57 ; \mathrm{p}=.000)($ Table 2).

A unit increase in PCGR was accountable for 1.98 reduction in total DS ( $B=-1.98 ; \beta=-.69 ; t=-7.49 ; p=.000) ; .45$ decrease in NM; .44 decrease in IEF; .38 decrease in IPP; .37 decrease in anhedonia and .35 decrease in NSE (See Table 2). Finally a unit increase in $C R$ accounts for 2.02 reduction in overall $D S(B=-2.02 ; \beta=-.62 ; t=-8.38$; $\mathrm{p}=.000) ;-.66$ decrease in $\mathrm{NM}(\mathrm{B}=-.66 ; \beta=-.73 ; \mathrm{t}=-8.31 ; \mathrm{p}=.000) ; .66$ decrease in ineffectiveness $(\mathrm{B}=-.66 ; \beta=-.69$; $\mathrm{t}=-7.51 ; \mathrm{p}=.000) ; .59$ reduction in IPP $(\mathrm{B}=-.59 ; \beta=-.72 ; \mathrm{t}=-8.11 ; \mathrm{p}=.000) ; .56$ reduction in anhedonia $(\mathrm{B}=-.56$; $\beta=-.67 ; \mathrm{t}=-7.03 ; \mathrm{p}=.000)$ and .55 reduction in NSE $(\mathrm{B}=-.55 ; \beta=-.69 ; \mathrm{t}=-7.65 ; \mathrm{p}=.000)$ dimensions.

\section{Discussion}

This study sought to investigate the predictive influence of resilience on depressive symptoms in a sample of adolescent with high functioning ASD. Generally, the study yielded several significant predictive impacts. Adolescents with high functioning ASD with higher levels of resilience reported lower levels of depressive 
symptoms. Both the total resilience score and the three resilience factor scores (individual resilience factors, primary caregivers' factors and the contextual factors) not only correlated significantly with the DS, but also were of significant negative predictive validity on all the DS dimensions. Individual resilience was the strongest predictor of all DS in this study, indicating that developing individual competences, including personal skills, peer support mechanisms and social skills decreases DS in adolescents with high functioning ASD. This affirms the findings of earlier studies (Kasari \& Sterling, 2014; De-la-Iglesia \& Olivar, 2015) that social isolation is one of the greatest risk factor of depression in adolescents with high functioning ASD. Social disabilities have been found to be linked with negative state of mind and depression in adolescents with high functioning ASD (Kasari \& Sterling, 2014). Adolescents with high functioning ASD tend to have interest in social interaction but often experience frustration due to lack of skills needed for successful social relationships (Kasari \& Sterling, 2014).

Given that adolescents with high functioning ASD have more peer contact and social stimulations compared to the low-functioning ones, the stress to navigate social situation may lead to depressive symptoms. Further, the results suggest that personal skill such as developing a positive sense of "self" self-confidence and competences to daily life activities could reduce depressive tendencies in adolescents with high functioning ASD skills (Huang, Hughes, Sutton, Lawrence, Chen, Ji, \& Zeleke, 2017). When an individual feel that they are competent and are able to navigate daily challenges, they tend to feel safer, are more independent, apply self-regulatory skills and are healthier. Such achievements and sense of competence boost their self-esteem and self-advocacy, giving them the impetus for decision making, problem-solving, life choices and goal setting/ accomplishments (Cabeza, Magill, Jenkins, Carter, Greiner, Bell, \& Lane, 2013; Todd, Reid, \& Butler-Kisber, 2010). As such the individual overrides the trauma arising from different inadequacies. These emphasize the importance of efforts towards helping adolescents with high functioning ASD to acquire skills for independence, executive functioning skills, practical skills, job skills, self-advocacy skills, social skills as well as developing a positive sense of self.

The primary caregivers resources subscale (physical care and psychological supports) was a significant negative predictor of depression in adolescents with high functioning ASD. This implies the high physical and psychological supports from caregivers such as parents and teachers decreases depressive symptoms in adolescents with high functioning ASD. This finding validates the previous studies that parental supports, parent-child interaction and teachers' support are linked to acquisition of social-emotional competence in adolescents with high functioning ASD (Mazefsky, Andrew, \& Santiago, 2016; Minke, Sheridan, Kim, Ryoo, \& Koziol, 2014). This implies that care-givers' relationships and attachment are important protective/resilience factor of depressive symptoms in adolescents with high functioning ASD. Given that adolescents with high functioning ASD are biologically vulnerable to depressive symptoms (Case-Smith et al., 2015; Mazefsky, 2015; Pitskel et al., 2014; Minke et al., 2014), the present study supports that building strong relationship with significant adult caregiver could be a feasible way of moderating biological depressive vulnerability in adolescents with high functioning ASD. Through physical and psychological supports, caregivers can help adolescents with high functioning ASD navigate their social-emotional and functional situations that could ordinarily constitute stress to such individual (Mazefsky et al., 2016; Minke et al., 2014). Thus, adolescents with high functioning ASD whose caregivers are responsive in these dimensions are more likely do demonstrate reduced depressive symptom.

Contextual resources (spirituality, education and cultural) subscale was found to be of negative links with all dimensions of depressive symptoms. Specifically CR was a strong predictor of negative mood, ineffectiveness, interpersonal problems, anhedonia and negative self-esteem. Adolescents with high functioning ASD who acquire the ability to benefit from educational experiences (Roux, Shattuck, Rast, Rava, \& Anderson, 2015), who have faith and are well adapted to their cultural contexts are less likely to feel depressed. Such individual tend to be more confident in them, are more optimistic and are likely to gain from contextual and interpersonal experiences. Results of this study also points to the importance of living within a culturally supportive environment in the adolescents with high functioning ASDs' resilience. Adolescents who are not stigmatized sail more in self-expression, self-esteem and self confidence. On the other hand, unsupportive cultural context (such as social exclusions, bullying, stigma and lacks) could limit intervention and expose adolescents with high functioning ASD to trauma that increases depression tendencies (Wilford, 2013). With these three skills, such individual are less likely to develop mental health problems like depression. Generally the findings of this study suggest that building resilience in adolescents with high functioning ASD could be a productive way of reducing depressive symptoms them.

A major limitation of this study is that it did not analyse data on any moderating variable such as gender, age, family socio-economic status and temperaments of the participants. Future studies may fill this gap. Further studies can also seek to find out intervention strategies for developing resilience in children and adolescents with autism. 


\section{Conclusion and Recommendations}

Given that resilience predicted depressive symptoms, it is concluded that poor resilience account to the high level of depressive symptoms among adolescents with high functioning autism. Reduction in the level of depressive symptoms among adolescents with high functioning ASD can be achieved through developing individual, relationship and contextual resilience skills among them. Both parents and special educators should intensify efforts in developing resilience in adolescents with high functioning ASD. Special services such as cognitive and occupational therapies, as well as resilience building interventions are recommended for adolescents with high functioning ASD in Nigeria.

\section{Competing Interests Statement}

The authors declare that there are no competing or potential conflicts of interest.

\section{References}

American Psychiatric Association. (2013). Diagnostic and statistical manual of mental disorders (5th ed.). Arlington, VA: American Psychiatric Publishing.https://doi.org/10.1176/appi.books.9780890425596

Anderson, K. A., Sosnowy, C., Kuo, A. A., \& Shattuck, P. T. (2018). Transition of individuals with autism to adulthood: a review of qualitative studies. Pediatrics, 141(Supplement 4), S318-S327. https://doi.org/10.1542/peds.2016-4300I

Anyan, F., \&Hjemdal, O. (2016). Adolescent stress and symptoms of anxiety and depression: Resilience explains and differentiates the relationships. Journal of affective disorders, 203, 213-220. https://doi.org/10.1016/j.jad.2016.05.031

Ashburner, J., Ziviani, J., \& Rodger, S. (2010). Surviving in the mainstream: Capacity of children with autism spectrum disorders to perform academically and regulate their emotions and behavior at school.Research in Autism Spectrum Disorders, 4(1), 18-27. https://doi.org/10.1016/j.rasd.2009.07.002

Bauminger, N., Solomon, M., \& Rogers, S. J. (2010).Predicting friendship quality in autism spectrum disorders and typical development.Journal of Autism and Developmental Disorders, 40(6), 751-761.https://doi.org/10.1007/s10803-009-0928-8

Bitsika, V., \&Sharpley, C. F. (2015). Differences in the prevalence, severity and symptom profiles of depression in boys and adolescents with an autism spectrum disorder versus normally developing controls. InternationalJournal of Disability, Development and Education, 62(2), 158-167. https://doi.org/10.1080/1034912X.2014.998179

Bitsika, V., Sharpley, C. F., \& Bell, R. (2013).The buffering effect of resilience upon stress, anxiety and depression in parents of a child with an autism spectrum disorder.Journal of Developmental and Physical Disabilities, 25(5), 533-543. 2013; 25(5): 533-543.https://doi.org/10.1007/s10882-013-9333-5

Brede, J., Remington, A., Kenny, L., Warren, K., \&Pellicano, E. (2017).Excluded from school: Autistic students' experiences of school exclusion and subsequent re-integration into school.Autism \& Developmental Language Impairments, 2, 2396941517737511. https://doi.org/10.1177/2396941517737511

Cabeza, B., Magill, L., Jenkins, A., Carter, E. W., Greiner, S., Bell, L., \& Lane, K. L. (2013).Promoting self-determination among students with disabilities: A guide for Tennessee educators.

Calder, L., Hill, V., \&Pellicano, E. (2013). 'Sometimes I want to play by myself': Understanding what friendship means to children with autism in mainstream primary schools. Autism, 17(3), 296-316. https://doi.org/10.1177/1362361312467866

Cappadocia, M. C., Weiss, J. A., \&Pepler, D. (2012).Bullying experiences among children and youth with autism spectrum disorders.Journal of autism and developmental disorders, 42(2), 266-277.https://doi.org/10.1007/s10803-011-1241-x

Case-Smith, J., Weaver, L. L., \&Fristad, M. A. (2015).A systematic review of sensory processing interventions for children with autism spectrum disorders.Autism, 19(2), 133-148. https://doi.org/10.1177/1362361313517762

Casey, B. J., Jones, R. M., Levita, L., Libby, V., Pattwell, S. S., Ruberry, E. J., ...\& Somerville, L. H. (2010). The storm and stress of adolescence: insights from human imaging and mouse genetics. Developmental Psychobiology: The Journal of the International Society for Developmental Psychobiology, 52(3), 225-235.https://doi.org/10.1002/dev.20447

Chinawa, J. M., Manyike, P. C., Aniwada, E. C., Chinawa, A. T., Obu, H. A., Odetunde, O. I., Nwokocha, A. R., 
\&Ibekwe, R. (2016). Prevalence and socioeconomic correlates of autism among children attending primary and secondary schools in south east Nigeria.African Health Sciences, 16(4). https://doi.org/10.4314/ahs.v16i4.8

DeFilippis, M. (2018).Depression in children and adolescents with autism spectrum disorder.Children, 5(9), 112. https://doi.org/10.3390/children5090112

De-la-Iglesia, M., \&Olivar, J. S. (2015).Risk factors for depression in children and adolescents with high functioning autism spectrum disorders.The Scientific World Journal, 2015. https://doi.org/10.1155/2015/127853

Feather, K. A. (2015). Low functioning to high functioning autism: A prescriptive model for counselors working with children across the spectrum. In the 56th Annual European Branch of the American Counseling Association Conference, Naples, Italy.

Garbacz, S. A., McIntyre, L. L., \& Santiago, R. T. (2016).Family involvement and parent-teacher relationships for students with autism spectrum disorders. School Psychology Quarterly, 31(4), 478.https://doi.org/10.1037/spq0000157

Gotham, K., Unruh, K., \& Lord, C. (2015).Depression and its measurement in verbal adolescents and adults with autism spectrum disorder.Autism, 19(4), 491-504. https://doi.org/10.1177/1362361314536625

Huang, A. X., \& Wheeler, J. J. (2006). High-functional autism: An overview of characteristics and related issues. International Journal of Special Education, 21(2), 109-123.

Huang, A. X., Hughes, T. L., Sutton, L. R., Lawrence, M., Chen, X., Ji, Z., \&Zeleke, W. (2017).Understanding the self in individuals with autism spectrum disorders (ASD): A review of literature.Frontiers in psychology, 8 , 1422. https://doi.org/10.3389/fpsyg.2017.01422

Kasari, C., \& Sterling, L. (2014).Loneliness and social isolation in children with autism spectrum disorders.R. J.Coplan, \&J. C.Bowker(pp. 409-426), The handbook of solitude: Psychological perspectives on social Isolation, social withdrawal, and being alone. Wiley, Chichester.https://doi.org/10.1002/9781118427378.ch23

Kirby, A. V., Bakian, A. V., Zhang, Y., Bilder, D. A., Keeshin, B. R., \& Coon, H. (2019). A 20-year study of suicide death in a statewide autism population.Autism Research, 12(4), 658-666.https://doi.org/10.1002/aur.2076

Kovacs, M. (2014).Children's Depression Inventory (CDI and CDI 2).The encyclopedia of clinical psychology, 1-5. https://doi.org/10.1002/9781118625392.wbecp419

Lai, M. C., \&Szatmari, P. (2019). Resilience in autism: Research and practice prospects.https://doi.org/10.1177/1362361319842964

Logan, D. E., Claar, R. L., Guite, J. W., Kashikar-Zuck, S., Lynch-Jordan, A., Palermo, T. M., ...\& Zhou, C. (2013). Factor structure of the children's depression inventory in a multisite sample of children and adolescents with chronic pain.The Journal of Pain, 14(7), 689-698.https://doi.org/10.1016/j.jpain.2013.01.777

Masten, A. S., \&Tellegen, A. (2012). Resilience in developmental psychopathology: Contributions of the project competence longitudinal study. Development and psychopathology, 24(2), 345-361. https://doi.org/10.1017/S095457941200003X

Matheis, Maya, \&Nicole C. (2016).Turygin."Depression and Autism."Handbook of Assessment and Diagnosis of Autism Spectrum Disorder(285-300).Springer, Cham, 2016.https://doi.org/10.1007/978-3-319-27171-2_15

Matson, J. L. (Ed.). (2016). Handbook of assessment and diagnosis of autism spectrum disorder.Springer. https://doi.org/10.1007/978-3-319-27171-2_15

Mazefsky, C. A. (2015). Emotion regulation and emotional distress in autism spectrum disorder: Foundations and considerations for future research.https://doi.org/10.1007/s10803-015-2602-7

Minke, K. M., Sheridan, S. M., Kim, E. M., Ryoo, J. H., \&Koziol, N. A. (2014). Congruence in parent-teacher relationships: The role of shared perceptions. The elementary school journal, 114(4), 527-546. https://doi.org/10.1086/675637

Pitskel, N. B., Bolling, D. Z., Kaiser, M. D., Pelphrey, K. A., \& Crowley, M. J. (2014). Neural systems for cognitive reappraisal in children and adolescents with autism spectrum disorder.Developmental cognitive neuroscience, 10, 117-128.https://doi.org/10.1016/j.den.2014.08.007

Roux, A. M., Shattuck, P. T., Rast, J. E., Rava, J. A., \& Anderson, K. A. (2015). National autism indicators report: 
Transition into young adulthood. Life Course Outcomes Research Program, AJ Drexel Autism Institute, Drexel University, Philadelphia, PA.

Salazar, F., Baird, G., Chandler, S., Tseng, E., O'sullivan, T., Howlin, P., ...\&Simonoff, E. (2015). Co-occurring psychiatric disorders in preschool and elementary school-aged children with autism spectrum disorder. Journal of Autism and Developmental Disorders, 45(8), 2283-2294.https://doi.org/10.1007/s10803-015-2361-5

Schiltz, H. K., McVey, A. J., Dolan, B. K., Willar, K. S., Pleiss, S., Karst, J. S., ... \& Van Hecke, A. V. (2018). Changes in depressive symptoms among adolescents with ASD completing the PEERS® social skills intervention.Journal of autism and developmental disorders, 48(3), 834-843.https://doi.org/10.1007/s10803-017-3396-6

Todd, T., Reid, G., \& Butler-Kisber, L. (2010).Cycling for students with ASD: Self-regulation promotes sustained physical activity.Adapted Physical Activity Quarterly, 27(3), 226-241.https://doi.org/10.1123/apaq.27.3.226

Ungar, M., \& Liebenberg, L. (2011). Assessing resilience across cultures using mixed methods: Construction of the child and youth resilience measure. Journal of Mixed Methods Research, 5(2), 126-149.https://doi.org/10.1177/1558689811400607

Wilford, A. (2015). Cultural variations in behaviours related to ASD in South African children.

\section{Copyrights}

Copyright for this article is retained by the author(s), with first publication rights granted to the journal.

This is an open-access article distributed under the terms and conditions of the Creative Commons Attribution license (http://creativecommons.org/licenses/by/4.0/). 